\title{
A água nos processos modeladores do relevo no domínio tropical: um mapa conceitual
}

\author{
Luciana Serelli Macedo Aranha \\ Geógrafa - Curso de Geografia - Departamento de \\ Geociências - DEGEO - Universidade Federal de São João \\ del-Rei - UFSJ- MG- Brasil \\ Iserelli@gmail.com \\ Carla Juscélia de Oliveira Souza \\ Doutora em Geografia - Curso de Geografia - Departamento \\ de Geociências - DEGEO - Universidade Federal de São \\ João del-Rei - UFSJ- MG- Brasil \\ carlaju@ufsj.edu.br
}

\begin{abstract}
WATER IN MODELLING PROCESSES OF THE RELIEF IN TROPICAL DOMAIN: A CONCEPTUAL MAP - A concept map is a teaching resource for teaching and learning, as long as the structure and organization allow us to represent the network connection established between processes, conditions and landforms. The paper presents, by means of a concept map, geomorphological processes related to the action of water in a tropical environment. The map was prepared for geography academic students, given the difficulties presented by them in understanding some concepts and developing Geomorphology's common reasoning. Although simplified, compared to the complexity of reality, the concept map proposed allows the understanding of the notion of process and system, identifies the role of water in the tropical environment, the notion of erosion, weathering, water resource and forms relief. Each student or reader interested in the topic presented can develop their own conceptual map, modify, reduce or enlarge it. Citation: Aranha L.S. M., Souz C.J.0. 2013. A água nos processos modeladores do relevo no domínio tropical: um mapa conceitual. Terræ Didatica, 9(2):94-104. < http://www. ige.unicamp.br/terraedidatica/>
\end{abstract}

KEYWORDS: Conceptual map, water, geomorphological processes, tropical environment.

RESUMO O mapa conceitual é um recurso didático favorável ao ensino e a aprendizagem, pois sua estrutura e organização permitem representar a rede de conexão estabelecida entre processos, condições e formas de relevo. O trabalho apresenta, por meio de um mapa conceitual, processos geomorfológicos relacionados à ação da água em ambiente tropical. O mapa foi elaborado para alunos de geografia, em formação acadêmica, dadas as dificuldades por eles apresentadas na compreensão de alguns conceitos e na elaboração de raciocínios comuns à Geomorfologia. Apesar de simplificado, se comparado com a complexidade do real, o mapa conceitual proposto possibilita a compreensão da noção de processo e sistema; permite identificar o papel da água no ambiente tropical, a noção de erosão, de intemperismo, de recurso hídrico e de formas de relevo. Cada aluno ou leitor interessado no tema apresentado pode elaborar seu próprio mapa conceitual, ao modificar, reduzir ou ampliar o modelo apresentado.

PALAVRAS-CHAVE: Mapa conceitual, água, processos geomorfológicos, ambiente tropical. 


\section{Introdução}

No processo de ensino e aprendizagem de alguns conteúdos das disciplinas do campo da Geomorfologia, verificam-se entre alunos de geografia dificuldades com alguns conceitos, como os de processos, sistemas, agentes, condicionantes e outros (Souza 2009). A dificuldade é percebida com maior transparência quando se trabalham conteúdos referentes à Geomorfologia Climática e Geomorfologia Ambiental. Verifica-se entre os graduandos o pensamento arraigado na visão linear do raciocínio, aplicada a processos, como herança do princípio da causalidade nas ciências naturais, além das dificuldades com conceitos. Diante desse fato, surgiu o interesse em desenvolver um mapa conceitual, a partir do qual as dificuldades de raciocínio e conceitual pudessem ser trabalhadas em prol de sua possível superação e a construção da noção de sistemas. O mapa elaborado e o texto que o acompanha, presentes neste trabalho, resultam de trabalho de conclusão de curso, defendido em junho de 2010.

O texto objetiva apresentar um mapa conceitual e discutir o trabalho da água em ambiente tropical, como um dos agentes participantes de diferentes processos geomorfológicos. O mapa conceitual como representação é também objeto de discussão, como recurso que pode ser utilizado no ensino de Geomorfologia.

A confecção do referido mapa demandou leituras referentes aos fundamentos, lógica, organização e importância desse tipo de representação no ensino-aprendizagem de conteúdos. Entre os autores que abordam o tema aprendizagem significativa e mapa conceitual, consideraram-se: Moreira (1997), Gava et al. (2009) e Alvarães (2008), os quais têm como referencial teórico as ideias de David Ausubel (1968). Para a elaboração do mapa conceitual com a temática "A água nos processos modeladores do relevo no domínio tropical", realizaram-se, também, leituras sobre intemperismo, erosão, escoamento superficial, infiltração e vários outros processos nos quais a água tem papel importante. Foram consultados, nessa fase de leitura, trabalhos de Christofoletti $(1972,1980,1981)$, Coelho Netto (1998), Guerra (1998, 1999), Tucci (2001), Suertegaray $(1997,2002,2008)$.

Com base nas discussões apresentadas por esses autores estudaram-se os seguintes tópicos: a) tipos de processos - decomposição, desagregação, transporte em vertentes e fluviais, depósitos, movimento de massas e outros; b) conceitos e noções chave intemperismo, vertente, condicionantes geológicos, canal fluvial, escoamento superficial, saturação, infiltração, perfil longitudinal e transversal e outros; e c) tipos de formas de relevo - desde as formas em escala geográfica local, como lapiéz, sulcos, depressões (dolinas, uvalas), vertentes, até formas em escala regional como serras, cristas, morros, entre outras. O estudo auxiliou a desenvolver raciocínios sobre a interação dos processos geomorfológicos, bem como na escolha e organização dos termos e conceitos na estrutura gráfica do mapa conceitual.

Para aferir a qualidade da representação do mapa conceitual confeccionado, e verificar se atendia aos propósitos didáticos do mesmo, o referido mapa foi apresentado a 21 alunos do $8^{\circ}$ período do Curso de Geografia, do Centro Universitário de Belo Horizonte (UNIBH), em 2010. Do total de alunos, quinze (15) responderam a um questionário e seis (6) participaram de entrevista sobre o mapa conceitual.

Os resultados mostraram que $67 \%$ dos entrevistados e $60 \%$ dos que responderam o questionário disseram compreender o papel do mapa conceitual e a conexão dos processos realizados pela água no ambiente tropical. E, ainda, $73 \%$ dos 21 alunos citaram que o mapa possibilita pensar e entender a noção de processos geomorfológicos e suas possíveis consequências e complexidade. Essas respostas e algumas sugestões apresentadas pelos alunos permitiram realizar pequenos ajustes no mapa conceitual final (Figura 1), o qual é discutido e desdobrado nos itens seguintes.

\section{Por que o mapa conceitual?}

De acordo com Gava et al. (2009, p. 3), os mapas conceituais "são representações gráficas de conceitos, semelhantes a diagramas, em um domínio específico de conhecimento, construído de tal forma que os relacionamentos entre os conceitos são evidentes" e podem facilitar o desenvolvimento de um texto escrito, assim como a leitura das ideias expressas graficamente. O mapa conceitual é uma das maneiras para se externalizar e organizar conhecimentos diversos (Moreira 1997). Apesar disso, o significado dos conceitos presentes no mapa é atribuído à compreensão pessoal, enquanto o leitor percorre a organização dos mesmos no mapa.

Essa organização é pensada como uma expressão que facilite o entendimento dos conceitos e suas conexões com outros e deve funcionar como 


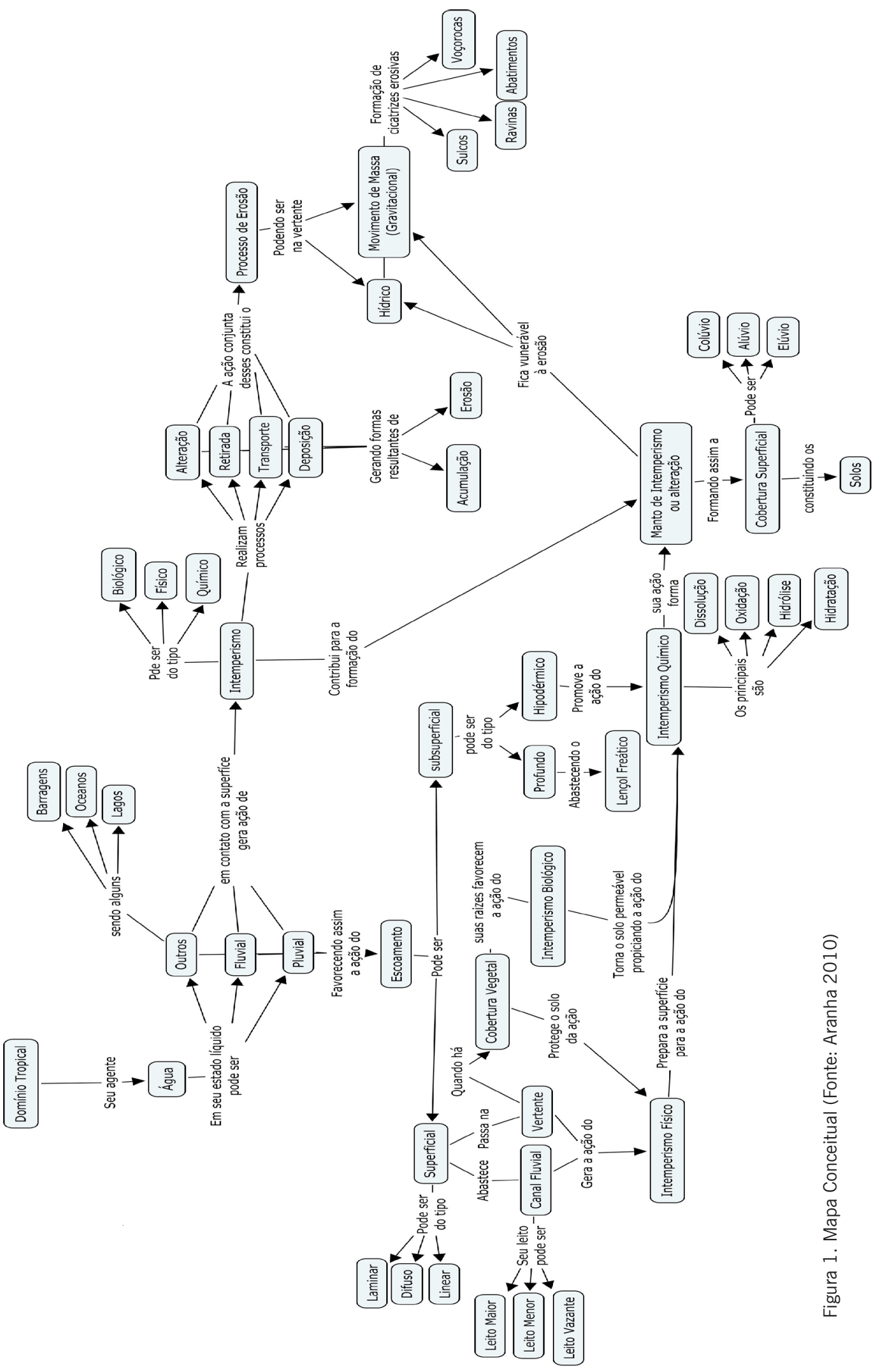


ferramenta de apoio tanto para o educando quanto para o educador, de forma distinta. Segundo Gava et al. (2009), o mapa pode ser utilizado, pelo professor, como um instrumento de avaliação, permitindo mensurar o crescimento do conhecimento de cada aluno, quanto à formação de conceitos, de ideias e raciocínio sobre um assunto.

O conhecimento prévio dos alunos referente aos conceitos e termos empregados é importante. Caso ocorra apenas uma noção do conceito, ainda assim é possível ao leitor compreender o mapa conceitual, pois o mapa deve ser um instrumento capaz de evidenciar significados atribuídos a conceitos, bem como a relações entre conceitos no contexto de um corpo de conhecimentos, de um campo do saber, de um conteúdo (Moreira 1997), no presente caso, os diferentes processos geomorfológicos em ambiente tropical.

A partir dos termos e conceitos presentes no mapa conceitual outros são citados em função do desdobramento da argumentação e da lógica que está se construindo. Entre os conceitos estão os subsunçores - palavras e frases acompanhadas de linhas de conexão entre conceitos - que ajudam o leitor a articular conceitos dentro de uma lógica de pensamento sistêmico e/ou linear. Quando se deseja acompanhar um único processo dentro do sistema maior, segue-se a leitura do mapa seguindo uma perspectiva linear, onde conceitos estão conectados pelos conceitos subsunçores.

Conforme explicado por Alvarães,

Os conceitos aparecem em caixas e os subsunçores entre um conceito e outro, o que determina a significação entre os dois conceitos criando uma unidade semântica. [...] O exercício de construção e análise de um mapa conceitual faz com que o aprendizado do sujeito se torne significativo através da própria necessidade do instrumento de buscar e analisar relacionamento de conceitos (Alvarães 2008,p.9).

$\mathrm{Na}$ aprendizagem significativa, os conhecimentos estão sempre se reorganizando de forma dinâmica. Tal reorganização depende da relação dos conhecimentos prévios do aprendiz com os novos obtidos por meio da observação, da experimentação, da reflexão no cotidiano ou no meio das disciplinas escolares ou acadêmicas. Para Pelizzari et al.(2002), a aprendizagem depende de duas condições: o aluno precisa ter disposição de aprender e o conteúdo tem que ser pontencializado de significado lógico. Conforme salienta Moreira,
Na aprendizagem significativa há uma interação entre o novo conhecimento e o já existente, na qual ambos se modificam [...]. A estrutura cognitiva está constantemente se reestruturando durante a aprendizagem significativa. O processo é dinâmico e o conhecimento vai sendo construído (Moreira 1997, p. 5).

Castellar e Moraes (2010, p. 99) afirmam que durante a construção do conhecimento o sujeito deve mobilizar "a capacidade de raciocínio, por meio da interligação de uma rede de conceitos que estruturam o conceito-chave que está sendo o principal". Nessa perspectiva, o mapa conceitual favorece o raciocínio do aluno quanto ao entendimento da rede de conceitos, que juntos expressam a noção de sistema e de processos geomorfológicos, em ambiente tropical.

Ainda segundo as autoras, "ao se apropriar de um conceito, o aluno precisa dar-lhe significado, inserir a nova informação para alterar esquemas, criando uma estrutura de pensamento" e, ainda, "a compreensão da palavra ou termo requer vários significados, que podem ser factuais ou epistemológicos, mostrando que, a partir de um conceito, pode-se obter outro ou analisar a sua relação com outros conceitos" (Castellar \& Moraes 2010, p.100).

Essa organização cognitiva, que a aprendizagem significativa busca para os conhecimentos, pode ser facilitada por meio do uso dos mapas conceituais, pois esses permitem descobrir e redescobrir outros conhecimentos, caracterizando uma aprendizagem prazerosa e possivelmente eficaz (Pelizzari et al. 2002).

A partir das respostas e comentários de alguns alunos do Curso de Geografia, que participaram da entrevista e do questionário, é possível verificar a percepção dos mesmos sobre o conteúdo representado no mapa conceitual, assim como algumas das ideias expressas por Moreira (1997) e Castellar e Moraes (2010), a saber:

O escoamento, bem explicado, mostra de forma clara os processos realizados pela água. Acho que todos os processos abordados no mapa estão bem amarrados e facilitam a compreensão.

Todos os conceitos explícitos no mapa conceitual podem trazer uma compreensão de forma rápida da dinâmica geomorfológica da água. Porém, acho que nosso conhecimento prévio é fundamental para essa compreensão.

Mesmo que ocorra uma incompreensão pode retomar a leitura de livros, artigos e etc. 
A partir das citações dos alunos é possível afirmar que a organização dada aos conceitos e termos, que compuseram o mapa conceitual, permitiu aos alunos compreendê-los. Mesmo aqueles que possuíam pouca afinidade com a matéria conseguiram responder às perguntas propostas. Durante a aplicação do questionário foi possível perceber certo encantamento dos alunos pela imagem do mapa conceitual, pois, sendo esse tão resumido e ao mesmo tempo complexo, expressa os caminhos que a água faz após atingir a superfície do terreno e o seu papel de agente modificador do relevo. A visualização da estrutura ramificada, sistêmica e a ligação desses conceitos é uma das dificuldades apresentadas por graduandos de Geografia.

\section{Geomorfologia e processos realizados pela água}

Ao abordar a questão do estudo do relevo, com destaque para a dinâmica externa, principalmente pela abordagem da Geomorfologia Climática, Christofolletti (1980) escreveu que os processos morfogenéticos são correlacionados às condições climáticas, as quais constituem importante fator na definição de agentes e mecanismos de atuação dos processos morfoclimáticos. Estes possuem dinâmica própria e compõem um conjunto maior, o sistema morfoclimático, que por sua vez responderá pela evolução e características das formas em domínios morfoclimáticos específicos (Christofoletti 1980). Portanto, pode-se afirmar que "processos morfogenéticos diferentes produzem formas de relevo diferentes, e que as características do modelado devem refletir até certo ponto as condições climáticas sob as quais se desenvolveu a topografia" (Christofoletti 1980, p.31).

A abordagem climática na Geomorfologia possibilitou ampliar os estudos geográficos pela abordagem sistêmica, cujos processos interagem em escalas espacial, regional e temporal geológica (tempo longo), sob diversos condicionantes (climáticos, biogeográficos, litológicos, estruturais e outros). A abordagem, pautada na ideia de morfogênese, permite ao aluno relacionar processos, formas, condicionantes e tempo transcorridos como modelo explicativo da evolução de uma paisagem - abordagem historicista (Mattos \& Souza 2010), mas torna difícil perceber a interação dos processos em outras escalas e entre escalas, sejam elas a espacial e a temporal (Souza 2009). Apesar disso, a contribuição dos conteúdos da Geomorfologia Climática para o tipo de raciocínio e visão sistêmica desenvolvida com alunos de geografia, na formação acadêmica, pode ser ampliada com a valorização e a atenção voltadas para os processos que ocorrem em escala espacial local ou regional e temporal curta, de horas, dias, meses e anos.

A questão de processos e escala de tempo curto e longo é bem apresentada por diversos autores, como Suertegaray $(1997,2002)$, que discute a natureza e os aspectos da abordagem da morfodinâmica e da morfogênese. Mattos e Souza (2010), fundamentados em Suertegaray $(1997,2002,2008)$ Vitte (2008) e Abreu (2003) também realizam discussão preliminar sobre as abordagens em geografia.

Nos parágrafos seguintes, a discussão não se prende necessariamente às abordagens da morfodinâmica ou morfogênese, mas em processos específicos que compõem um todo integrado. $\mathrm{O}$ conjunto, compreendido em suas particularidades e conexões, possibilita ao leitor compreender a ideia de processos e sistemas e assim aplicar o conhecimento a situações diversas, sem a preocupação de explicar a evolução ou a projeção de formas. A tarefa fica livre ao pensamento do leitor.

\section{Os processos da água em domínio tropical}

No domínio tropical, a água é um dos elementos que se encontra em abundância, devido ao alto índice de precipitação que a região recebe durante o ano, cujo valor varia de região para região, de lugar para lugar, assim como a sua distribuição ao longo do ano. De acordo com Demangeot (2000) o índice varia de 900 a $2000 \mathrm{~mm}$ anuais e a distribuição ocorre entre 6 a 9 meses no ano. Esses valores elevados e a sua ocorrência em grande parte do ano fazem com que a água seja transformada em um importante agente responsável por modelar o relevo através de diversos processos, como os erosivos (mecânico ou químico). As palavras de Coelho Netto reforçam e ampliam essa informação:

A água constitui um dos elementos físicos mais importantes na composição da paisagem terrestre, interligando fenômenos da atmosfera inferior e da litosfera, e interferindo na vida vegetal, animal e humana, a partir da interação com os demais elementos do seu ambiente de drenagem. Dentre as múltiplas funções da água destacamos seu papel como agente modelador do relevo da superfície terrestre, controlando tanto a formação como o comportamento mecânico dos mantos de solos e rochas, [...] (Coelho Netto 1998, p.93). 
A água que possui ciclo natural é um fenômeno global de circulação fechada, passa por três estados - sólido, líquido, gasoso - e constitui um processo que ocorre na atmosfera e na superfície terrestre (Silveira 2001). Neste texto, discute-se parte desse ciclo, o estado líquido, destacando-se mais precisamente a precipitação e seus caminhos depois de atingir o solo, conforme se visualiza na Figura 1 - "Mapa Conceitual”. O ciclo hidrológico tem parte constituída pela circulação da água na superfície terrestre, o que significa verificar a circulação da água no interior e na superfície dos solos e das rochas, bem como nos oceanos e nos seres vivos (Silveira 2001).

Para Guerra et al. (1999, p. 24-25),

O ciclo hidrológico é de importância fundamental para o processo erosivo, pois parte da água da chuva cai diretamente no solo, outra parte é interceptada pela cobertura vegetal [...]. A água pode tomar vários caminhos: primeiro causa o splach, depois se infiltra, aumentando o teor de umidade no solo, podendo saturar o solo e, finalmente, pode se armazenar nas irregularidades do solo, formando, as poças (poods), que eventualmente poderão dar início ao escoamento superficial.

Com a precipitação, desencadeiam-se os processos de escoamento superficial e subsuperficial que, por sua vez, permitem a movimentação da água na superfície. O conceito de precipitação, em hidrologia, refere-se à "água proveniente do meio atmosférico que atinge a superfície terrestre" (Bertoni \& Tucci 2001, p.177). Conhecer a intensidade e a distribuição anual da precipitação é importante para possível controle de inundação e da erosão do solo. Esse conhecimento, no campo da Geomorfologia, possibilita entender, em parte, a magnitude e a frequência de alguns processos hídricos e gravitacionais responsáveis por feições erosivas nas vertentes.

Segundo Coelho Netto (1008, p. 100),

A precipitação é um importante fator-controle do ciclo hidrológico e, portanto, da regulagem das condições ecológicas e geográficas de uma determinada região. As quantidades relativas de precipitação (volume), seus regimes sazonais ou diários (distribuição temporal) e as intensidades de chuvas individuais (volume/duração) são algumas características que afetam a natureza e a magnitude do trabalho geomorfológico $[\ldots]$.

Para Silveira (2001) e Coelho Netto (1998), a água precipitada, ao entrar em contato com a super- fície, percorre diversos caminhos. A água pode escoar na superfície ou infiltrar no solo dependendo das características texturais e estruturais dos solos atingidos. Essas características são um dos aspectos que influenciarão na quantidade de água de chuvas que infiltrará ou excederá para escoar na superfície do terreno.

As águas superficiais e subsuperficiais ocupam superfícies distintas, nas quais realizam processos semelhantes, que podem ser: a) processos mecânicos de retirada, transporte e deposição e b) processos químicos que alteram os minerais contidos nas rochas e contribuem para a elaboração de outros. Os processos favorecem indiretamente a alimentação da vida biótica, a qual desencadeia processos biológicos na superfície e na subsuperfície, ao mesmo tempo em que os processos erosivos contribuem para a modelagem do relevo.

A cobertura vegetal exerce um duplo papel nos processos de modelagem do relevo: protege o solo da ação da água e exerce ação mecânica sobre a superfície, por meio de suas raízes. A densidade da cobertura vegetal é fator importante na remoção de sedimentos, no escoamento superficial e na perda de solo, pois minimiza os impactos das gotas de chuva, diminuindo assim a erosão e a impermeabilização do solo. Por outro lado, as raízes podem ajudar na formação de agregados e contribuir para o intemperismo químico, ao se ramificarem no solo (Guerra 2001).

No processo de alteração da superfície, as ações coletivas dos intemperismos físico, químico e biológico são responsáveis pela produção de detritos a serem erodidos. De acordo com Suertegaray (2008, p. 65), intemperismo é concebido com um "conjunto de processos advindos da exposição contínua da rocha à ação de agentes atmosféricos e biológicos que promovem a desintegração mecânica e a decomposição química desta”. O tipo químico e bioquímico é responsável pela decomposição das rochas e o intemperismo físico é responsável pela fragmentação das mesmas (Christofoletti 1980).

A ação mecânica que os intemperismos físicos e biológicos realizam na superfície, favorece o intemperismo químico, pois torna a superfície mais permeável e friável e com isso a água infiltra para o interior da rocha, desencadeando processos químicos. Por meio dos processos químicos desenvolvem-se a cobertura superficial e a formação dos solos (Coelho Netto 2001). O material que reveste a rocha sã, denominado, também, de manto de alteração, pode apresentar diferentes espessuras, 
de acordo com a sua posição na topografia, com a declividade do terreno, com a natureza da rocha, com o manejo do solo, da cobertura vegetal e, também, segundo a relação avanço da frente de intemperismo e processo de desnudação. A existência do manto de alteração favorece a atuação dos processos hídricos e gravitacionais nas encostas.

Os processos erosivos hídricos provocados no contato da água de precipitação com o manto de alteração, aliados aos intemperismos físico-químicos e biológicos e aos movimentos de massa, promovem em tempos curtos (histórico) formas que hoje são observadas na escala do vivido e percebido.

\section{Água subsuperficial e intemperismo químico}

A água tem acesso ao meio subterrâneo por meio do processo de infiltração no solo. A infiltração e a percolação no interior do solo são comandadas pelas tensões capilares nos poros e pela gravidade. A umidade do solo é realimentada pela infiltração, sendo aproveitada em parte pelos vegetais, que a absorvem pelas raízes, mas a água que o solo não absorve percola para o lençol freático (Silveira 2001).

De acordo com Suertegaray (2008), o escoamento subsuperficial divide-se em hipodérmico e profundo, sendo que no hipodérmico o fluxo de água permeia os horizontes do solo e, dependendo da concentração nos túneis ou dutos, podem causar erosão significativa na superfície situada acima, como as voçorocas. Já no escoamento profundo, também conhecido como fluxo de água subterrânea, o fluxo de água permeia as camadas rochosas possibilitando a formação de aquíferos ou lençol freático, quando esse fluxo fica "confinado" entre rochas.

A água proveniente da precipitação, rica em oxigênio $\left(\mathrm{O}_{2}\right)$, em contato com a atmosfera, onde há a presença do gás carbônico $\left(\mathrm{CO}_{2}\right)$, adquire caráter ácido (Toledo et al. 2000). A água "ácida", quando entra em contato com a rocha causa alteração nos minerais, favorecendo a pedogênese e os processos erosivos. De acordo com Toledo et al. (2000, p.141),

A pedogênese (formação do solo) ocorre quando as modificações causadas nas rochas pelo intemperismo, além de serem químicas e mineralógicas, tornam-se, sobretudo estruturais, com importante reorganização e transferência dos minerais formadores do solo [...] entre os níveis superiores do manto de alteração.
O manto de alteração é uma cobertura natural das rochas e apresenta-se inconsolidado, composto por fragmentos de rochas e de solo, incluindo o solo transportado (colúvio e alúvio), solos autóctones (elúvio) e depósitos residuais. Esse manto facilita o desenvolvimento da vida vegetal e propicia condições a vida na Terra.

O manto de alteração passa basicamente por duas fases, sendo solúvel e residual. Na fase solúvel, os constituintes das rochas intemperizadas são transportados pelas águas que drenam o manto. $\mathrm{Na}$ fase residual, o material que resta no manto de alteração torna-se potencialmente enriquecido com constituintes menos solúveis, resistindo assim à ação intempérica (Toledo et al. 2001).

\section{Água superficial}

O escoamento superficial ocorre nas encostas durante a chuva, quando a capacidade de armazenamento de água no solo é saturada. O escoamento divide-se em difuso, laminar ou linear. $\mathrm{O}$ escoamento difuso ocorre em áreas com cobertura vegetal, através de filetes anastomosados e sem hierarquia; o laminar ocorre em áreas sem cobertura vegetal, escoando como uma lâmina, onde as águas se deslocam de forma dispersa sobre a superfície. O escoamento linear ocorre quando as águas concentram-se e possuem maior atuação erosiva, fixando leitos e gerando, na superfície, ravina e voçorocas (Suertegaray 2008). O tipo de escoamento vai interferir na quantidade de material físico e/ou químico que será retirado e transportado na vertente e, consequentemente, nas características das cicatrizes erosivas que podem surgir.

Para Bigarella (2003), o escoamento superficial desempenha um papel importante no mecanismo erosivo, pois a ação desse mecanismo está vinculada ao transporte do material solto, obtido a partir do salpicamento (ação da gota de chuva - splash), ou da concentração em filetes em ravinas, sulcos ou ranhuras. A intensidade do fenômeno erosivo depende da velocidade do escoamento, combinado com a tipologia e a declividade das vertentes, do tipo de solo e cobertura vegetal e da ação gravitacional. Ainda, de acordo com Bigarella (2003, p. 918),

A erosão, o transporte e a deposição são processos que não podem ser separados. Eles são interdependentes dentro de relações constantemente mutáveis do fluxo de carga existente. A capacidade de erosão de um fluxo depende mais das partículas por ele transportadas do que do volume de água. A ação corrosiva 
tende eliminar a rugosidade da superfície. O fluxo aumenta para a jusante, assim como sua carga. Com a diminuição do fluxo, ocorre a deposição.

O intemperismo físico é compreendido como "todo o processo que causa desgaste das rochas, com separação dos grãos minerais antes coesos e com sua fragmentação, transformando a rocha inalterada em material descontínuo e friável" (Toledo et al. 2000, p.141). A água superficial e a cobertura vegetal contribuem para tal processo. A cobertura vegetal, por meio do intemperismo biológico, causa a fragmentação das rochas, devido ao crescimento de suas raízes, propiciando, assim, uma maior exposição do material desagregado ao ar e à água, facilitando a ação do intemperismo químico (Toledo et al. 2000).

\section{Vertente e canal fluvial}

Os processos citados acima contribuem para a dinâmica das vertentes e estas não podem ser compreendidas separadamente do canal fluvial. De acordo com Christofoletti (1980) e Suertegaray (2008) as vertentes são formas tridimensionais, que se estendem do interflúvio ao canal fluvial, apresentam a superfície topográfica como limite superior e a superfície rochosa inalterada como limite inferior e tal superfície é modelada por processos morfológicos. Em sua própria dinâmica e evolução as vertentes fornecem materiais a serem transportados pelo canal fluvial. A vertente é, também, zona de abastecimento dos reservatórios subterrâneos, por meio do escoamento subsuperficial profundo.

Conforme Bertolini (2010, p. 56-57),

Vertente é um termo técnico cujo emprego implica concepção da dinâmica do relevo através do escoamento superficial da água que se processa das partes mais altas do terreno para as partes mais baixas, no fundo de vale [...]. A configuração do relevo em temos de inclinação e direção das vertentes está diretamente relacionada ao escoamento superficial da água e, consequentemente, ao papel que essa água desempenha na superfície, seja em termos dos processos morfodinâmicos seja quanto aos locais do terreno onde ela poderá se acumular.

A unidade vertente pode ser dividida em três partes - alta, média e baixa - nas quais podem ser identificados processos geomorfológicos essenciais para entendê-la. De acordo com Christofoletti (1980), na alta vertente localizam-se o interflúvio e a zona de abastecimento (infiltração) dos reser- vatórios subterrâneos. Nessa área, encontram-se processos de pedogênese, associados ao movimento vertical do escoamento superficial, à atuação mecânica e à química da água subsuperficial.

Na média vertente, localizam-se a encosta, o declive de transporte e o sopé. Essa parte é uma área propícia à atuação dos intemperismos físico e químico, resultando possíveis desmoronamentos e deslizamentos, os quais produzirão material detrítico que será transportado. No sopé é realizada a reposição de material pelos movimentos coletivos, pelo escoamento superficial, pela formação de cones de dejeção e pelo transporte de materiais.

$\mathrm{Na}$ baixa vertente localizam-se o declive aluvionar, a margem do canal fluvial e o leito do canal fluvial. Na porção da baixa vertente ocorrem vários processos como depósitos aluvionares, ação da água subsuperficial e corrasão na margem, enquanto no leito do canal fluvial ocorre transporte de material para jusante, com a ação da água superficial. $\mathrm{O}$ material do leito se deve à gradação periódica e a corrasão das margens (Christofoletti 1980).

Um canal fluvial é um local drenado pelas águas do rio que, por sua vez, funciona como canal de escoamento (Christofoletti 1981) e pode ter diferente extensão e largura. De acordo com o tipo de vale e a sazonalidade das águas que escoam o canal pode apresentar leito maior, menor e vazante.

O leito maior compreende a ocupação da planície fluvial, regularmente ocupada pelas cheias anuais, enquanto o leito menor compreende o local delimitado pela calha do canal de drenagem, geralmente, bem definida pelas margens (Christofoletti 1981). O leito vazante está contido no leito menor e é ocupado pelas águas baixa, principalmente no período da estiagem, no domínio tropical.

O material que chega ao canal fluvial é transportado pela água e passa a participar do contínuo processo de retrabalho do fundo e das margens do leito fluvial. O trabalho do rio confere ao canal tipos distintos de formas, de acordo com a interação de diversos condicionantes, como declividade do perfil longitudinal, litologia, aporte de sedimentos, competência de transporte e outros. O material que o rio transporta e deposita nas planícies e no fundo do leito é chamado de alúvio, o qual constitui um tipo de cobertura superficial.

\section{Um todo integrado e complexo: 0 Mapa conceitual}

Os processos descritos variam em escala espacial e temporal; são específicos, integrados e ocorrem de 
maneira simultânea, variando a intensidade, a frequência e a magnitude. Embora tratados individualmente, como abordagem didática para especificar cada um, os processos devem ser percebidos e concebidos de maneira integrada ao sistema geomorfológico. $\mathrm{O}$ todo integrado e complexo, expresso como uma imagem gráfica de rede, figura 2, partes são percebidas dentro da estrutura e revelam a "dominância" de um conceito ou ideia, aqui denominados de dimensão.

Cada dimensão refere-se a um possível desdobramento que pode ser discutido pelo professor para a construção de outros conhecimentos. Cada dimensão pode, ou não, fazer referência aos processos e ao raciocínio sistêmico, mas possibilita:

1. contextualizar a água no ambiente (porção superior à esquerda do mapa);

2. discutir a noção de erosão (porção superior à direita);

3. entender os processos hídricos integrados (porção inferior à esquerda);

4. relacionar intemperismo e manto de alteração (porção inferior central) e

5. relacionar processos e cicatrizes erosivas (porção inferior à direita).

Cada uma das cinco dimensões apresentadas no Mapa conceitual, figura 2, possibilita novas interações, como a do contexto da água no ambiente marinho e os tipos de erosão e formas resultantes ou, ainda, o contexto da água pluvial, em ambiente semi-árido e sua conexão com a dimensão escoamento superficial e subsuperficial, intemperismo e possíveis formas resultantes.

A lógica de raciocínio contida nessas cinco dimensões se aplicada para outros ambientes bioclimáticos abre espaço para a inclusão dos aspectos intensidade, frequência e magnitude dos processos, em função da presença de outros agentes e condicionantes, como litologia, estrutura, tectônica e ação antrópica.

De acordo com Souza (2009), na prática cotidiana do ensino a ação de simplificar os fenômenos geográficos como meio para torná-los compreensíveis pelos alunos contribui para o pensamento parcial que compõe um todo integrado. Portanto, há momentos, durante o ensino, que o abordar a parte se faz necessária. Em outro momento é fundamental que as partes possam ser percebidas e concebidas, também, como um todo integrado e complexo. O mapa conceitual possibilita a visualização do todo integrado, ainda que simplificado diante da realidade dos processos geomorfológicos.

\section{Considerações finais}

É possível dizer que este trabalho é ao mesmo tempo a socialização de um percurso de estudos e pesquisa, quanto o próprio resultado da pesquisa a produção de um texto e de um mapa conceitual, que ajudem a entender o papel da água na modelação do relevo, em ambiente tropical.

A possibilidade de eficiência do mapa conceitual foi verificada quando o mesmo foi apresentado a alunos de Geografia em fase de conclusão do curso. Nessa etapa do curso, acredita-se que os alunos tenham capacidade de pensar, reconhecer e discutir conteúdos desenvolvidos ao longo de sua formação. O conhecimento dos alunos levou-os a pensarem nos conceitos e noções que entendiam e nas dificuldades que tinham na época que cursaram a disciplina geomorfologia e, ainda, permitiu aos alunos esboçarem o quanto o mapa conceitual possibilitou a visualização dos processos e a interação entre os mesmos.

A leitura do mapa pelos alunos mostrou o exercício que os mesmos realizavam durante a inferência das informações, como a de identificar os processos, via os conceitos e a pensar na interação entre os conceitos do sistema. E, ainda, a escolha de caminhos estabelecidos pela relação termos conexões e reflexões a partir do conceito água, como agente no domínio tropical. Cada nova escolha implicava retornar para alguns pontos (conceitos) anteriormente percorridos, a fim de se seguir outro caminho a partir daquele ponto, como em uma rede. Essa dinâmica possibilitou aos alunos verificarem, além da existência de diversos e simultâneos processos, as possibilidades de raciocínio e leituras.

Mesmo utilizando a ideia do agente água em ambiente tropical, como um recorte para descrição e análise de processos, o exercício de objetivar o complexo não foi tarefa fácil, embora prazerosa na medida das descobertas sobre as possibilidades de ligações de termos. As autoras reconhecem que algumas definições foram contempladas superficialmente no texto e que a partir das mesmas poderiam emergir outras discussões. A necessidade de estabelecer limites entre escrita, representação, reflexão e objetivos almejados resultou em escolhas, (inclusão e exclusão), sem deixar de lado o cuidado para não criar equívocos conceituais, nem de inviabilizar o objetivo inicial.

O mapa conceitual e o texto não finalizam aqui, ficam em aberto para aqueles que vislumbrem novas possibilidades de conexão e discussão sobre 


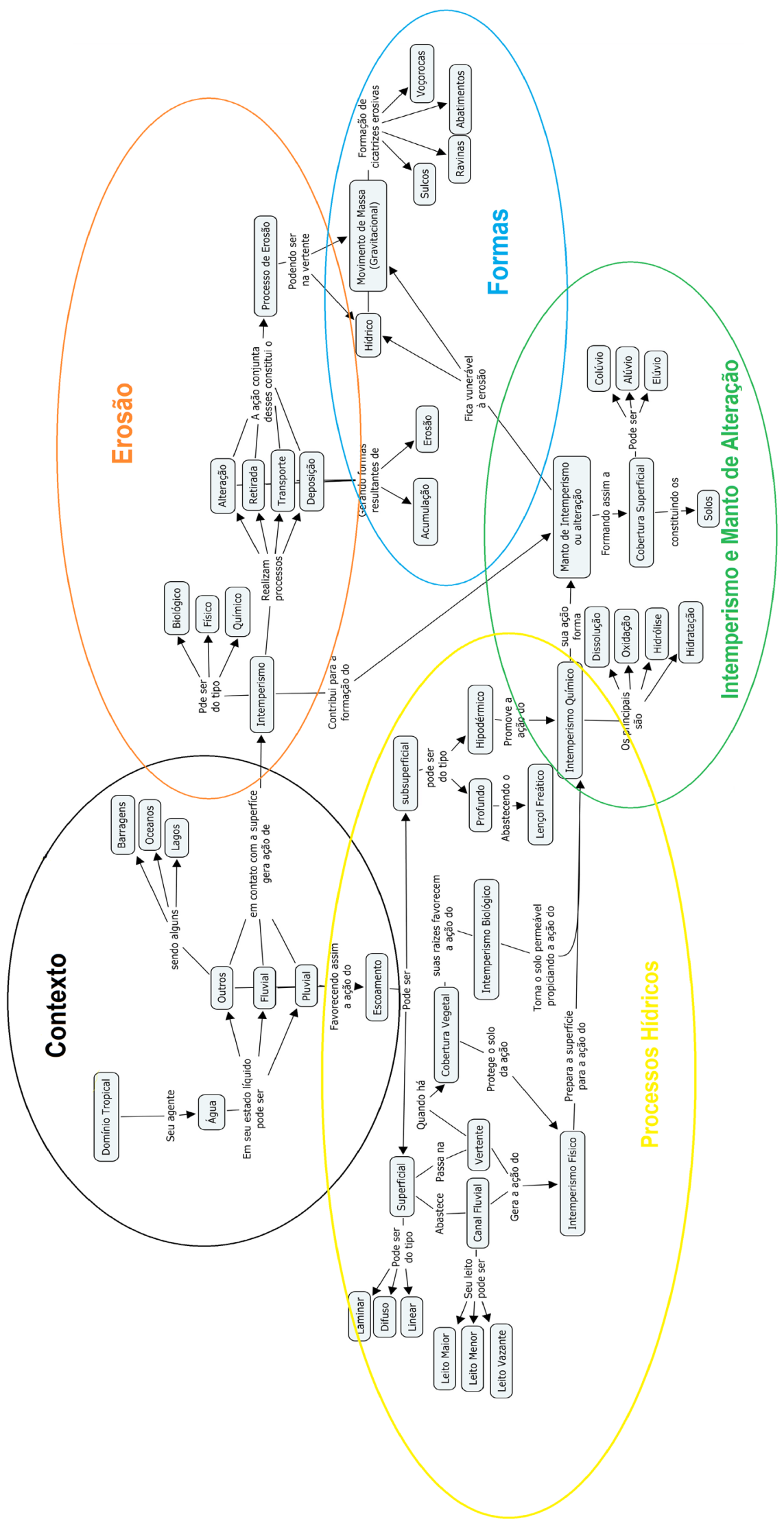

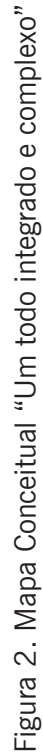


a água em ambiente tropical, via outros mapas conceituais.

\section{Referências bibliográficas}

Abreu A.A. 1983. A teoria geomorfológica e sua edificação: análise crítica. São Paulo: Revista IG, 4(1/2):5-23.URL: http://www.igeologico.sp.gov. br/downloads/revista_ig/v4n1-2a01.pdf Acesso 16.05.2010.

Alvarães A.C.T. 2008. Utilização de mapas conceituais no ensino superior como instrumento de análise de resolução de problemas através da aprendizagem significativa. In: Semin. Nac. de Pesq. em Educação, 2, 2008, Santa Cruz do Sul. Anais..., Santa Cruz do Sul: UNISC. 16p. URL: www.albertoalvaraes.adm.br/artigosacademicos/mapas_conceituais_unisc.pdf. Acesso: 25.02.2010.

Aranha L.S.M. 2010. Água nos processos modeladores do relevo no domínio tropical: Um mapa conceitual. Belo Horizonte: Centro Univ. Belo Horizonte (UNIBH). 19f. (Trab. Concl. Curso Grad. Geografia).

Bertolini W.Z. 2010. O ensino do relevo no contexto da educação científica e geográfica: noções e propostas para uma didática da geomorfologia. Belo Horizonte. Inst. Geoc., Univ. Fed. Minas Gerais. 105 f. (Dissert. Mestr. Geografia).

Bertoni J.C., Tucci C.E.M. 2001. Precipitação In: Tucci C.E.M. org. 2001. Hidrologia: Ciência e aplicação. 3. ed. Porto Alegre: Ed. UFRGS/ABRH. 4 v., cap. 5, p. 177-241.

Bigarella J.J. 2003. Erosão superficial. In: Bigarella J.J. 2003. Estrutura e origem das paisagens tropicais e subtropicais. Florianópolis: UFSC. v. 3, p. 909-928.

Castellar S.M.V., Moraes J.V. 2010. O significado da construção dos conceitos. In: Castellar S.M.V., Moraes J.V. 2010. Ensino de geografia. São Paulo: Cengage Learning. p. 99-118.

Christofoletti A. 1980. Geomorfologia. 2. ed. São Paulo: Ed. Blücher. 188p.

Christofoletti A. 1981. Geomorfologia Fluvial. São Paulo: Ed. Blücher. 313p.

Christofoletti A. 1972. O Desenvolvimento da Geomorfologia. Campinas: Notícia Geomorfológica. 12(13):13-30.

Coelho Netto A.L. 1998. Hidrologia de encosta na interface com a geomorfologia In: Guerra A.J.T., Cunha S.B.da. 1998. Geomorfologia: uma atualização de bases e conceitos. 3. ed. Rio de Janeiro: Bertrand Brasil, cap. 3, p. 93-148.

Demangeot J. 2000. Os meios naturais do globo. Tradução de F. Ribeiro Martins e H. Nogueira Santo. Lisboa: Fund. Calouste Gulbenkian, 478 p. (Tít. Orig.: Les Milieux Naturels du Globe).
Gava T.B.S., Menezes C.S. de, Cury, D. 2009. Aplicações de Mapas conceituais na educação como ferramenta metacognitiva. Vitória: UFES. 11p. URL: http://www.nte-jgs.rct-sc.br/mapas.htm. Acesso:10.09.2009.

Guerra A.J.T. 1999. Início do processo erosivo. In: Guerra, A.J.T., Silva A.S., Botelho R.G.M. 1999. Erosão e conservação dos solos: conceitos, temas e aplicações. Rio de Janeiro: Bertrand Brasil, cap. 1, p. 17-55.

Guerra A.J.T. 1998. Processos erosivos nas encostas. In: Guerra, A.J.T., Cunha S.B. da. 1998. Geomorfologia: uma atualização de bases e conceitos. 3. ed. Rio de Janeiro: Bertrand Brasil. cap. 4, p. 149-209.

Marinho E.G.do A. 1995. Desenvolvimento e natureza da geomorfologia. Campinas: Cadernos IG/ Unicamp, 5(1):9-21.

Mattos F.C. de O., Souza, C.J. de O. 2010. Geomorfologia: uma discussão preliminar sobre as abordagens morfogênese e morfodinâmica e a Geografia. In: Encontro Nacional de Geógrafo, 10. 2010. Porto Alegre. Anais... Porto Alegre: AGB. 10 p.

Moreira M.A. 1997. Mapas conceituais e aprendizagem significativa. Porto Alegre: Instituto de Física,UFRGS, 11 p. URL:www2.iq.usp.br/docente/famaxim/disciplina/integrada/mapasport-Moreira.pdf> Acesso: 3.10.2010.

Silveira A.L.L. 2001. Ciclo hidrológico e bacia hidrográfica. In: Tucci, C.E.M.org.2001. Hidrologia: Ciência e aplicação. 3. ed. Porto Alegre: Editora UFRGS:ABRH, v. 4. cap. 2, p. 35-52.

Souza C.J.de O. 2009. Geomorfologia no ensino superior: difícil, mas interessante! Por quê? Uma discussão a partir dos conhecimentos e das dificuldades entre graduandos de geografia. Belo Horizonte: Inst. Geoc. UFMG. 268 f. (Tese de Dout. Geografia).

Suertegaray D.M.A. 1997. Geomorfologia: novos conceitos e abordagens. In: Simpósio Brasileiro de Geografia Física Aplicada, 7, 1997, Curitiba. Anais... Curitiba. p. 24-30.

Suertegaray D.M.A. (Org.). 2008. Terra feições ilustrada. 3. ed. Porto Alegre: Ed. UFRGS. 264p.

Suertegaray D.M.A. 2002. Tempos longos... tempos curtos... na análise da Natureza. Vitória, Geografares, p. 159-163.

Toledo M.C.M.; Oliveira S.M.B.de, Melfi A.J. 2000. Intemperismo e Formação do Solo. In: Teixeira W., Toledo M.C.M.de, Fairchild T.R., Taioli F. 2000. Decifrando a Terra. São Paulo: Ofic. Textos. cap. 8, p. 139-166.

Vitte A.C. 2008. A Construção da Geomorfologia Brasileira: as transformações paradigmáticas e o estudo do relevo. Santa Maria: Geografia: Ensino \& Pesquisa, 12(2):44-54. 